\title{
A Retrospective Cohort Study on the Invasive Fungal Infection in the Preterm Infants
}

\author{
Dan Dang, Xin $\mathrm{Mu}$, Jian Tang, Shuhan Huang and Hui $\mathrm{Wu}^{*}$ \\ Department of Neonatology, the First Hospital of Jilin University, Changchun 130021, China \\ ${ }^{*}$ Corresponding author
}

\begin{abstract}
Background: Invasive fungal infection has become the most serious and urgent problem that needs to be solved in tertiary center in China. The aim of this retrospective cohort study was to clarify the pathogenesis and identify the high risk group of invasive fungal infection of premature infants in Chinese population. Methods: The research sample population includes1, 138 premature infants who are in the hospital for more than two days from January 1, 2013 to January 1, 2017 in a tertiary center of the First Hospital of Jilin University, Changchun, China. A retrospective cohort study was used to regard the relationship between ten suspicious disease risk factors and one protection factor proposed in the previous foreign literature: Male, small gestational age, low birth weight, asphyxia after birth, Peripherally inserted central catheter, mechanical ventilation, human cytomegalovirus infection, combination with bacterial infection, the use of spectrum antibiotic and glucocorticoid, fluconazole prophylaxis and invasive fungal infection of premature infants. Results: There are 77 cases premature infants with invasive fungal infection in our center. The main pathogens are smooth candida yeast $(47 \%)$ and saccharomyces albicans $(\mathbf{4 1 . 5 \% )}$ ) in our unit. Peripherally inserted central catheter $(\mathrm{OR}$ value $=4.983, \mathrm{P}<0.001)$, human cytomegalovirus infection ( $O R$ value $=4.088, P<0.001)$, broad-spectrum antibiotics application (OR value $=2.839, \mathrm{P}=$ $0.026)$, and mechanical ventilation $(O R$ value $=2.811, P=0.002)$ are independent risk factors of premature infants with invasive fungal infection. Conclusion: Human cytomegalovirus infection, peripherally inserted central catheter, mechanical ventilation and broad-spectrum antibiotics application are independent risk factors of premature infants with invasive fungal infection.
\end{abstract}

Keywords - invasive fungal infection; premature infants; relevant factors

\section{INTRODUCTION}

The presence of yeasts in samples of normally sterile deep tissue or closed body cavity, such as blood, peritoneal fluid, cerebrospinal fluid and urine which gathered through catheterization or suprapubic puncture has been referred to as invasive fungal infections (IFIs). With the development of the skill of the neonatal intensive care, IFIs has become an important part of nosocomial infection in neonatal intensive care units (NICU), the morbidity of invasive fungal infection is $0.57-2.9 \%$ [1,2]which accounts for $6.8 \%-12 \%[3]$ of nosocomial infection.

Preterm infants whose gestational age (GA) less than 37 weeks, especially the ELBW infant, due to their relative immunodeficiency, immature skin structure, repeated invasive procedures and the prolong use of broad-spectrum antibiotics, are at high risk of developing IFIs. There were lots of researches about IFIs in premature infant till now and founded the risk factors associated with IFIs include male, younger gestational age, low birth weight, asphyxia after birth, receipt of broad-spectrum antibiotics, Peripherally inserted central catheter (PICC), mechanical ventilation and prior steroid therapy[4-10]. In addition, the prophylaxis of fluconazole to prevent IFIs is still controversial [11-14]. In the recent years, some scholars raise doubts: on one hand, the fluconazole prophylaxis may decrease the occurrences of invasive fungal infection, but have nothing to improve with the mortality; on the other hand, the knowledge about pharmacological and pharmacokinetic of fluconazole in prematurity are limited, so the dosage and the duration are not clear.

\section{MATERIALS AND METHODS}

\section{A. Research Object and Method}

This retrospective cohort study was conducted at the First Hospital of Jilin University, Changchun, China. The research sample population includes whose gestational age less than 37 weeks and who were hospitalized for more than two days from from January 1, 2013 to January 1, 2017. The ethical approval was received prior to conducting this study. A data collection form was made and all data were collected from the patients chart in the hospital. End point of observation was 140 days after birth, discharge or death

\section{B. Grouping and Outcome}

All the research objects that meet the standard were divided into an exposure group and a control group according to exposure factors which were included ten suspicious high risk factors and one suspicious protective factor. Suspicious high risk factors include male, earlier premature infants whose gestational age less than 34 weeks, low birth weight infant whose birth weight less than $1500 \mathrm{~g}$, asphyxia after birth which were diagnosis as Apgar score less than 5 at 5 minute after delivery, PICC, mechanical ventilation, HCMV infection which were diagnosis as the major matrix phosphoprotein 65 (pp65) of cytomegalovirus positive, combination with bacterial infection which was diagnosis as positive bacterial culture of blood, cerebrospinal fluid or urine, the use of spectrum antibiotic which was diagnosis as three-generation or above cephalosporin and carbapenem antibiotic before the fungal positive training, application of glucocorticoid before the fungal positive training. Suspicious protective factor was using fluconazole for more than three days before the fungal positive culture. Outcome was invasive fungal infection which was 
diagnosis as fungal culture positive of blood, cerebrospinal fluid or urine for premature infants with/without onset.

\section{Statistical Method}

All exposure factors were calculated to see whether they were independent risk factors or protective factor for the disease through the inspection of single factor $\chi^{2}$ and the unconditional logistic regression of multi-factors. The data were retrospectively collected. The 11 items of the exposure factors related to the invasive fungal infection of premature infants were assigned values (Table 1 ). The single factor $\chi 2$ test analysis was conducted, that was, the foundation of the data analysis for the preliminary screening of variables. In order to avoid information lost, the exposure factors with $\mathrm{P}<0.1$ would be listed as standard, the significant variable was taken into the logistic regression equation as an independent variable. Whether each exposure factor was related to the invasive fungal infection of premature infants was clarified and the OR value and its $95 \%$ confidence interval was calculated, SPSS11.5 software was adopted for data analysis.

TABLE I. THE CHARACTERISTICS OF PREMATURE INFANTS WITH FUNGAL INFECTION

\begin{tabular}{|c|c|c|c|c|c|c|c|}
\hline & Numbers & $\begin{array}{l}\text { white candida } \\
\text { yeast } \\
\text { (n) }\end{array}$ & $\begin{array}{c}\text { non-white } \\
\text { candida yeast } \\
\text { (n) }\end{array}$ & $\begin{array}{l}\text { Hospital Stay } \\
\text { (d) }\end{array}$ & Onset Time (d) & $\begin{array}{l}\text { Cure } \\
\text { (n) }\end{array}$ & $\begin{array}{l}\text { Death } \\
\text { (n) }\end{array}$ \\
\hline \multicolumn{8}{|l|}{ Gender } \\
\hline Male & 45 & 21 & 24 & 35.53 & 16.02 & 32 & 13 \\
\hline $\begin{array}{c}\text { Female } \\
\text { GA }\end{array}$ & 32 & 11 & 21 & 37.81 & 19.68 & 22 & 10 \\
\hline$<28 \mathrm{~W}$ & 0 & 0 & 0 & 0 & 0 & 0 & 0 \\
\hline $\begin{array}{c}32-37 \\
\text { BW }\end{array}$ & 44 & 16 & 28 & 35.5 & 17.35 & 31 & 13 \\
\hline$<1000 \mathrm{~g}$ & 1 & 1 & 0 & 18 & 6 & 0 & 1 \\
\hline $1000-1499 \mathrm{~g}$ & 30 & 11 & 19 & 40.43 & 18.37 & 18 & 12 \\
\hline $1500-2499 \mathrm{~g}$ & 44 & 18 & 26 & 34.32 & 17.12 & 35 & 9 \\
\hline$>2500 \mathrm{~g}$ & 2 & 1 & 1 & 34 & 21 & 1 & 1 \\
\hline
\end{tabular}

\section{RESUltS}

\section{A. Basic Information}

Finally, 6,638 premature infants were included. Among them, 77 premature infants were diagnosis as invasive fungal infection. The characteristics of premature infants with fungal infection as table 2 . For premature infants with birth weight more than $2500 \mathrm{~g}$, between $1500 \mathrm{~g}$ and $2500 \mathrm{~g}$, between $1000 \mathrm{~g}$ and $1500 \mathrm{~g}$, the morbidity was $0.85 \%$ (2 cases in 235 cases), $6.09 \%$ (44 cases in 722 cases), 8.29\% (30 cases in 164 cases) respectively. For premature infants with birth weight less than $1000 \mathrm{~g}$, the morbidity was $5.55 \%$ ( 1 case in 18 cases). It showed there were inverse relationship between the morbidity rate and the birth weights among the premature infants with birth weights more than $1000 \mathrm{~g}$.

TABLE II. THE LENGTH OF HOSPITAL STAYS COMPARISON FOR PREMATURE INFANTS WITH/WITHOUT INVASIVE FUNGAL INFECTION

\begin{tabular}{cccccc}
\hline Fungi infection & $\mathrm{n}$ & P50 (P25, P75) & Mean rank & Z & P \\
\hline Yes & 77 & $33(22,47)$ & 921.81 & -9.748 & $<0.001$ \\
No & 1061 & $13(7,22)$ & 543.93 & &
\end{tabular}

\section{B. Short-Term Prognosis and Pathogens Distribution}

The median length of the hospital stay was 13 days for premature infants without fungal infection, and that were 7 days and 22 days in 25 th percentile and 75 th percentile. The median length of the hospital stay was $33(22,47)$ days for premature infants with invasive fungal infection. The two were of significant difference (Table 2). Among the invasive fungal infection cases, there were 36 cases with smooth Candida yeast (47\%), 32 cases with candida albicans $(41.5 \%)$, 3 cases with tropical candida yeast (4\%), 2 cases with nearly smooth candida (2.5\%), 2 cases with candida lusitaniae $(2.5 \%)$ and 2 cases with an unknown candida yeast (2.5\%), including one case in which the patients had both an unknown candida yeast infection (11 days after birth) and a smooth candida yeast infection (17 days after birth).

\section{Risk Factors Analysis}

The exposure factors that may be meaningful to premature infants with invasive fungal infection include: PICC, Broad-spectrum antibiotics, invasive assisted ventilation, HCMV infection, bacterial infection, young gestational age, prophylactic use of fluconazole, low birth weight, glucocorticoids application. The above factors were all of statistical significance $(\mathrm{P}<0.01)$. Factors that have no obvious effect on disease were excluded: Male and asphyxia after birth (Table 3). Many exposure factors with statistical significance in the single factor analysis result were conducted by a gradual unconditional logistic regression analysis. PICC, HCMV infection, broad-spectrum antibiotics application and invasive mechanical ventilation were independent risk factor for premature infants with invasive fungal infection. They were of significant difference (Table 4). 
TABLE III. SINGLE FACTOR X2 TEST ANALYSIS RESULT FOR PREMATURE INFANTS WITH INVASIVE FUNGAL INFECTION

\begin{tabular}{|c|c|c|c|c|c|c|c|}
\hline \multirow{2}{*}{\multicolumn{2}{|c|}{ Exposure factors }} & \multicolumn{2}{|c|}{ Invasive fungal infection } & \multirow{2}{*}{$\mathrm{RR}$} & \multirow{2}{*}{$95 \% \mathrm{CI}$} & \multirow{2}{*}{$\chi^{2}$} & \multirow{2}{*}{$P$} \\
\hline & & Yes $(\%)$ & No $(\%)$ & & & & \\
\hline \multirow{2}{*}{ Gender } & Male & 0.982 & $0.63 \sim 1.52$ & 0.982 & $0.63 \sim 1.52$ & 0.006 & 0.936 \\
\hline & Female & & & & & & \\
\hline \multirow{2}{*}{ Asphyxia after birth } & Yes & 0.887 & $0.39 \sim 1.98$ & 0.887 & $0.39 \sim 1.98$ & 0.086 & 0.770 \\
\hline & No & & & & & & \\
\hline \multirow{2}{*}{ HCMV infection } & Yes & 5.646 & $3.72 \sim 8.56$ & 5.646 & $3.72 \sim 8.56$ & 74.134 & $<0.001$ \\
\hline & No & & & & & & \\
\hline \multirow{2}{*}{ PICC } & Yes & 9.932 & $6.28 \sim 15.70$ & 9.932 & $6.28 \sim 15.70$ & 142.329 & $<0.001$ \\
\hline & No & & & & & & \\
\hline \multirow{2}{*}{ Mechanical ventilation } & Yes & 7.961 & $4.86 \sim 13.02$ & 7.961 & $4.86 \sim 13.02$ & 96.653 & $<0.001$ \\
\hline & No & & & & & & \\
\hline \multirow{2}{*}{$\begin{array}{l}\text { Broad-spectrum } \\
\text { antibiotics }\end{array}$} & Yes & 8.821 & $3.86 \sim 20.12$ & 8.821 & $3.86 \sim 20.12$ & 41.146 & $<0.001$ \\
\hline & No & & & & & & \\
\hline \multirow{2}{*}{ Glucocorticoids } & Yes & 2.799 & $1.61 \sim 4.849$ & 2.799 & $1.61 \sim 4.849$ & 13.399 & $<0.001$ \\
\hline & No & & & & & & \\
\hline \multirow{2}{*}{ Bacterial infection } & Yes & 4.829 & $3.08 \sim 7.56$ & 4.829 & $3.08 \sim 7.56$ & 49.739 & $<0.001$ \\
\hline & No & & & & & & \\
\hline \multirow{2}{*}{ Fluconazole prophylaxis } & Yes & 4.087 & $2.67 \sim 6.25$ & 4.087 & $2.67 \sim 6.25$ & 47.942 & $<0.001$ \\
\hline & No & & & & & & \\
\hline \multirow{2}{*}{ Birth weight } & $<1.5 \mathrm{Kg}$ & $31(17.1)$ & $150(82.9)$ & 3.563 & $2.32 \sim 5.46$ & 36.625 & $<0.001$ \\
\hline & $\geq 1.5 \mathrm{Kg}$ & $46(4.8)$ & $911(95.2)$ & & & & \\
\hline \multirow{2}{*}{ Gestational age } & $<34$ weeks & $61(11.1)$ & $487(88.9)$ & 4.105 & $2.39 \sim 7.03$ & 31.926 & $<0.001$ \\
\hline & $\geq 34$ weeks & $16(2.7)$ & $574(97.3)$ & & & & \\
\hline
\end{tabular}

TABLE IV. THE UNCONDITIONAL LOGISTIC REGRESSION ANALYSIS RESULT OF MULTI-FACTORS FOR PREMATURE INFANTS WITH INVASIVE FUNGAL INFECTION

\begin{tabular}{|c|c|c|c|c|c|c|}
\hline Risk factors & $\mathrm{b}$ & S.E. & Wald & $\mathrm{P}$ & OR & $95 \% \mathrm{CI}$ \\
\hline HCMV infection & 1.408 & 0.297 & 22.498 & $<0.001$ & 4.088 & $2.285 \sim 7.315$ \\
\hline PICC & 1.606 & 0.303 & 28.03 & $<0.001$ & 4.983 & $2.75 \sim 9.031$ \\
\hline Mechanical ventilation & 1.034 & 0.328 & 9.906 & 0.002 & 2.811 & $1.477 \sim 5.352$ \\
\hline $\begin{array}{l}\text { Broad-spectrum } \\
\text { antibiotics }\end{array}$ & 1.044 & 0.47 & 4.94 & 0.026 & 2.839 & $1.131 \sim 7.126$ \\
\hline
\end{tabular}

\section{DisCUSSION}

The research result shows that the morbidity was different for premature infants with different birth weights, there were inverse relationship between the morbidity rate and the birth weights among the premature infants with birth weights more than $1000 \mathrm{~g}$. But, the morbidity rate of the extremely low birth weight infants in this study was only $5.55 \%$, maybe because there were few infants in this group. IFIs increased the mortality of premature infants and extend the length of hospital stay.

The research finds that HCMV infection, PICC, mechanical ventilation and broad-spectrum antibiotics application are independent risk factors of premature infants with IFIs. When the body is infected by the cytomegalovirus, 
the function of thymus and spleen will be damaged. Premature infants with congenital cytomegalovirus infection are easy to merge conditioned pathogen infection which includes fungus. For premature infants who need PICC, the related infection of preventive venous catheter is more meaningful, including peripheral vascular selection, aseptic operation, and the application of small dose of heparin, the appropriate maintaining of pump speed, avoiding the infusion of blood products, and pulling out central venous catheter timely. As a normal flora in oral cavity, candida albicans enter into the lung through trachea cannula with oral secretion, form colonization, gradually intrude into the lower respiratory tract and then cause systemic infection. The main pathogens of severe entilator-associated pneumonia are pseudomonas aeruginosa and candida albicans. Therefore, it is important to standardize tracheal intubation, shorten mechanical ventilation time. On one hand, the application of broad-spectrum antibiotics damages the balance of normal flora in the body. Cotten Compared with the application of narrow-spectrum antibiotics, empirical application of broad-spectrum antibiotics cannot reduce the morbidity and mortality of nosocomial bacterial infection. By contrast, it will cause disastrous multiple drug-resistant bacteria infections and secondary IFIs. Therefore, for the application of broad-spectrum antibiotics, treatment drugs need to be taken seriously and the prophylaxis should be taken as little as possible.

In addition, the result of the prevention application fluconazole in a single factor $\chi^{2}$ test analysis shows that the morbidity of prophylaxis group is 4.087 times higher than the control group. But when listed as the Logistic regression analysis of many factors, the result shows the prophylaxis has no obvious effect on the incidence of disease. The reason for the result may be that the prophylaxis used in our center is selective. Patients in the fluconazole prophylaxis group are more severe with birth weight less than $1500 \mathrm{~g}$, more than 2 weeks using of broad-spectrum antibiotics and who need PICC or assisted ventilation. All these factors may increase the IFIs bur not the occurrence of IFIs caused by the application of fluconazole prevention. Therefore, when other exposure interference factors are excluded in the multi-factor analysis, preventive application of fluconazole is not the independent risk factor of IFIs.

In conclusion, the reduction of invasive manipulation, mechanical ventilation and center venipuncture time is emphasized for the prevention of IFIs of premature infants. At the same time, the application indication of antibiotics should be controlled and the broad-spectrum antibiotics application should be reduced.

The study also has shortcomings. First, the sample population consists of premature infants from a certain period of time in one center. It needs to be conducted in multiple centers and with the dynamic monitoring. Second, the prognosis analysis of premature infants with IFIs is limited to disease mortality and length of stay. Long-term outcome such as neurology, viscera function damage and complication are necessary to follow-up in the further.

\section{COMPETING INTERESTS}

The authors have declared that no competing interest exists.

\section{REFERENCES}

[1] López Sastre JB, Coto Cotallo GD, Fernández Colomer B. Neonatal invasive candidiasis: a prospective multicenter study of 118 cases. American Journal of Perinatology 2003; 20(3): 153-163.

[2] Austin NC, Darlow B. Prophylactic oral antifungal agents to prevent systemic candida infection in preterm infants.Cochrane Database Syst Rev 2004; (1): CD003478.

[3] Bendel, Catherine M. Nosocomial Neonatal Candidiasis. Pediatr Infect Dis J 2005; 24(9): 831-832.

[4] Michael Cotten, Scott McDonald, Barbara Stoll, et al. The association of third-generation cephalosporin use and invasive candidiasis in extremely low birth-weight infants. Pediatrics. 2006; 118(2): 717-22.

[5] Sano H, Kuroki Y. The lung collectins, SP-A and SP-D, modulate pulmonary innate immunity. Molecular immunology. 2005; 42 (3): 279-87.

[6] Wright JR. Immunoregulatory functions of surfactant proteins. Nature review immunology. 2005; 5(1):58-68

[7] Rowen JL, Rench MA, Kozinetz CA, et al. Endotracheal colonization with Candida enhances risk of systemic candidiasis in very low birth weight neonates. J Pediatric. 1994; 124(5):789-94

[8] Benjamin DK Jr, Stoll BJ, Gantz MG, et al. Neonatal candidiasis: epidemiology, risk factors, and clinical judgment. Pediatrics. 2010; 126(4):e865-73.

[9] Feldman C, Kassel M, Cantrell J, et al. The presence and sequence of endotracheal tube colonization in patients undergoing mechanical ventilation. Eur Respir J. 1999; 13:546-51.

[10] Apisarnthanarak A, Holzmann-Pazgal G, Hamvas A, et al. Ventilator associated pneumonia in extremely preterm neonates in a neonatal intensive care unit: characteristics, risk factors, and outcomes. Pediatrics. 2003; 112(6):1283-89.

[11] Kaufman, DA. Fluconazole prophylaxis: can we eliminate invasive Candida infections in the neonatal ICU? Curr Opin Pediatr. 2008; 20(3):332-40.

[12] Kuzucu C, Durmaz R, Otlu B, et al. Species distribution, antifungal susceptibility and clonal relatedness of Candida isolates from patients in neonatal and pediatric intensive care units at a medical center in Turkey. New Microbiol. 2008; 31(3):401-8.

[13] Chapman RL. Prevention and treatment of Candida infections in neonates. Semin Perinatol, 2007, 31:39-46.

[14] Procianoy RS, Eneas MV, Silveira RC. Empiric guidelines for treatment of Candida infection in high-risk neonates. Eur J Pediatr, 2006, 165:422-423. 